\title{
Effect of Temperature on the Chemical Composition and Physicochemical Properties of Diester Aviation Lubrication Oil
}

\author{
Ting Yao, ${ }^{1}$ Na Zhang, ${ }^{2}$ Jianqiang Hu, ${ }^{3}$ Xiaoxiao Liao, ${ }^{4}$ Yongli Shen, ${ }^{4}$ and Zhuoting Gan (D) \\ ${ }^{1}$ Analysis and Test Center, Huangshan University, Huangshan 245041, China \\ ${ }^{2}$ School of Chemistry and Chemical Engineering, Huangshan University, Huangshan 245041, China \\ ${ }^{3}$ Department of Aviation Oil, Air Force Logistics College, Xuzhou 221006, China \\ ${ }^{4}$ Unit 94923 of People's Liberation Army of China, Wuyishan 354301, China \\ ${ }^{5}$ School of Tourism, Huangshan University, Huangshan 245041, China \\ Correspondence should be addressed to Zhuoting Gan; ztgan73@126.com
}

Received 12 June 2020; Revised 26 July 2020; Accepted 26 August 2020; Published 4 September 2020

Academic Editor: Rui Wu

Copyright (c) 2020 Ting Yao et al. This is an open access article distributed under the Creative Commons Attribution License, which permits unrestricted use, distribution, and reproduction in any medium, provided the original work is properly cited.

\begin{abstract}
High temperature is the main factor responsible for degrading the lubrication and antiwear properties of aero-lubricating oils. Accordingly, this study assessed the effects of thermal treatment of diester aviation lubricating oil and the associated mechanism. Fourier-transform infrared spectroscopy and gas chromatography/mass spectrometry analyses showed that low-molecularweight compounds, such as monoesters, diesters, alcohols, and olefins, were the primary degradation products. An assessment of the degradation mechanism of bis(2-ethylhexyl)decanedioate showed that pyrolysis, resulting in the cleavage of $\beta$-C-H and C-C bonds, was the main process involved. Additional investigation using advanced polymer chromatography showed that the molecular weights of oil samples changed slightly at high temperatures, while the viscosity and viscosity-temperature index values were relatively stable. High-pressure differential scanning calorimetry established that the thermal oxidation stability of these oils decreased above $250^{\circ} \mathrm{C}$. Finally, variations in the chemical compositions of the oil samples were found to be highly correlated with changes in physicochemical properties during thermal processing, with the formation of low-molecular-weight polar compounds greatly increasing the acid numbers of the oils.
\end{abstract}

\section{Introduction}

The lubricating oils employed in engines have various important functions, such as cooling the engine, reducing abrasion by friction, and eliminating corrosive agents $[1,2]$. Furthermore, just as human blood analysis can be used to assess the presence of disease, oil analysis can provide important information to facilitate early detection of machine failure [3]. With continued development in the aeronautical industry, the operating temperature of modern aeroengines has increased above $160^{\circ} \mathrm{C}$, while turbine bearings can be heated as high as $280^{\circ} \mathrm{C}$. When the cooling air flow is stopped, the bearing temperature can even exceed $400^{\circ} \mathrm{C}$ [4]. The performance of aero-lubricating oils (ALOs) inevitably deteriorates at such high service temperatures, with this process receiving increasing attention as an important risk factor in the field of aviation [5].
In contrast to mineral-based oils, synthetic lubricating oils (SLOs) are synthesized to perfectly match various working environments, based on modifying the molecular structure and function for the actual intended application [6]. Several different SLOs have been developed, including polyethers, esters, and synthetic hydrocarbons. However, SLOs based on synthetic hydrocarbons with sufficiently low viscosity and low acid number (AN) values at high temperatures can be difficult to obtain [7]. Ester oils prepared by dehydration and esterification reactions of acids and alcohols are relatively homogeneous [8], and ester lubricating oils (ELOs) show excellent resistance to thermal oxidation and wear, as well as low temperature fluidity, low volatility and toxicity, superior lubricating characteristics, and biodegradability [9-11]. Therefore, these oils can play important roles, such as lubricating, cooling, antirusting, and 
sealing, under the harsh operating conditions found in aerospace applications and other industrial environments $[12,13]$. The performance of ELOs is closely correlated with their molecular structure and chemical composition, while the viscosity and viscosity index of ELOs are largely determined by molecular conformation. Specifically, longer main carbon chains result in higher viscosity, viscosity index, and pour point values. However, both the viscosity and viscosity index increase, while the pour point decreases, when side chains are introduced [14]. The thermal decomposition and antioxidant characteristics of ester oils are also affected by their molecular structure, although thermal decomposition and oxidation mechanisms are different for different oils [15].

High temperature is the primary factor responsible for reducing the lubricating effect of an ALO. Thermal stress not only induces cracking, oxidation, and polymerization [16] but also affects the physical adsorption of oil films on various surfaces. Specifically, high temperature can cause desorption, leading to the loss of oriented adsorption or melting of the oil film [17]. Furthermore, ELOs bearing various molecular structures exhibit different forms of degradation at high temperatures. Bian et al. [18] found that high temperatures, particularly hot spots, are among the main factors responsible for oil degradation. Meanwhile, Jiang reported that seven different ester-based lubricating oils subjected to high temperatures showed visible differences in degradation and stability [19]. Zong et al. [20] also reported that the viscosity of some ALOs was less affected by heating at $300^{\circ} \mathrm{C}$, while Fan et al. [21] evaluated the physicochemical and tribological properties of synthetic ester lubricating oils isooctyl furan dicarboxylate (isooctyl-FD), isooctyl adipate (isooctyl-A), and isooctyl sebacate (isooctyl-S). Isooctyl-FD was determined to have thermal and oxidation stabilities comparable to those of isooctyl-A and isooctyl-S. The friction-reduction and antiwear properties of isooctyl-FD were observed to be superior, while its viscosity changes with temperature and low-temperature properties were inferior. $\mathrm{Wu}$ et al. [16] investigated the oxidative degradation products of di-2-ethylhexyl sebacate (DEHS) by Fouriertransform infrared spectroscopy (FTIR) and gas chromatography-mass spectrometry (GC-MS). The results showed that oxidation and pyrolysis were the primary degradation processes of DEHS and that 2-ethyl-1-hexanol and mono(2ethylhexyl) sebacate were the major degradation products. Additionally, some highly polar products were formed that had the potential to significantly improve the antiwear and friction-reducing properties of DEHS. Therefore, the performance of ALOs is largely dependent on their molecular structures and chemical compositions.

Although high-pressure differential scanning calorimetry (PDSC) can be used to assess the resistance of oils to oxidation at high temperatures, using this technique to explore the mechanism of high-temperature oxidative degradation at the molecular level is difficult [22-24]. Therefore, a number of modern analytical techniques have been proposed as alternatives. Kohler et al. [25] studied changes in ester-based ALOs employed in civil aviation aircraft after long-term usage. The Kohler group examined molecular-level degradation using electrospray ionization (ESI)-MS, liquid chromatography (LC)-ESI-MS, and LC-tandem MS. Frauscher et al. [26] investigated the decomposition of bis(2-ethylhexyl) adipate containing 4,4'-methylene-bis(2,6-di-tert-butylphenol) using ${ }^{18} \mathrm{O}_{2}$ labelling with GC coupled with electron ionization MS, determining that the $\mathrm{C}-\mathrm{O}$ ester bond was the primary site for oxidative attack. Qian et al. [27] examined the thermal oxidation mechanism of dioctyl adipate (DOA) using GC-MS and visual reactive force field molecular dynamics (ReaxFF $\mathrm{MD}$ ). The results indicated that the AN increased significantly and the tribological properties were improved owing to the formation of highly polar carboxylic acids and low-molecularweight monoesters. Jin et al. [28] compared the decomposition of DOA to that of triisodecyl trimellitate (TDTM) using both PDSC and ReaxFF MD and proposed atomic-level oxidation mechanisms for both compounds. TDTM was found to have superior resistance to oxidation owing to dissociation of the $\mathrm{C}-\mathrm{O}$ bond in the alcohol chain being initiated for TDTM, while the C-O bonds in alcohol and ester groups in DOA were susceptible to oxidation. A greater number of DOA degradation fragments were identified, along with the formation of a polymerized product, while TDTM evidently did not generate any larger molecules.

The compositions of diester aero-lubricating oils (DEALOs) are complex (comprising base oils and various additives), and these materials have useful physical properties, including oxidative stability, good lubrication properties, and wear resistance, stability under extreme pressures, and high flash points. The properties of these substances are affected by temperature, load, and engine speed, resulting in uncertain and random degradation of physicochemical properties during service. Therefore, the degradation processes and products of DEALOs vary significantly based on their specific molecular structures. The effects of these structures on the stability of diesters have been investigated $[16,29,30]$, although there have been few reports concerning changes in the structure and composition of DEALOs at elevated temperatures. Therefore, in-depth investigations of the structure-performance relationship associated with DEALOs during thermal treatment (TT) will provide a better understanding of the effects of TT on tribological performance. Additionally, information concerning changes in chemical composition will assist in evaluating the application limitations of DEALOs.

In this study, DEALOs were subjected to TT at 180, 200, $230,250,270$, and $300^{\circ} \mathrm{C}$. The treated specimens and a fresh oil sample were then fully characterized using a number of different analytical techniques, and the effects of TT on the physicochemical properties of the materials were investigated. Furthermore, correlations between the oil molecular structures and physicochemical properties (kinematic viscosity, viscosity index, AN, oxidation value, and degradation products) were also examined.

\section{Materials and Methods}

2.1. Materials. The DEALO sample was supplied by Unit 94923 of the People's Liberation Army of China. This material comprised bis(2-ethylhexyl) decanedioate (BEHDD) as a base 
oil together with additives including antioxidants, antifoaming agents, and preservatives. The kinematic viscosity $(\mathrm{KV})$ of the sample at $100^{\circ} \mathrm{C}$ was $\geq 3.2 \mathrm{~mm}^{2} \mathrm{~s}^{-1}$, the acid number was $\leq 0.2 \mathrm{mg} \mathrm{KOH} \mathrm{g}^{-1}$, and the specified operating temperature range was ${ }^{-} 60$ to $200^{\circ} \mathrm{C}$. All solvents used in the experiments were commercially purchased analytical-grade reagents that were purified by distillation prior to use.

2.2. Sample Preparation. In each trial, a DEALO $(150 \mathrm{~mL})$ was heated for $2 \mathrm{~h}$ at $180,200,230,250,270$, or $300^{\circ} \mathrm{C}$ in a 500 $\mathrm{mL}$ stainless steel autoclave with stirring at $1,000 \mathrm{rpm}$ under the ambient air atmosphere with no pressurization. Each sample was subsequently cooled and filtered to obtain specimens referred to herein as $\mathrm{DE}_{180}, \mathrm{DE}_{200}, \mathrm{DE}_{230}, \mathrm{DE}_{250}$, $\mathrm{DE}_{270}$, and $\mathrm{DE}_{300}$, respectively. An untreated oil sample stored at room temperature $\left(\mathrm{DE}_{\mathrm{r}}\right)$ was used as a reference sample.

2.3. Chemical Characterization. The $\mathrm{DE}_{180}, \mathrm{DE}_{200}, \mathrm{DE}_{230}$, $\mathrm{DE}_{250}, \mathrm{DE}_{270}, \mathrm{DE}_{300}$, and $\mathrm{DE}_{\mathrm{r}}$ specimens were characterized by FTIR spectroscopy (Nicolet 380, Thermo Fisher, USA), GC-MS (Hewlett-Packard 7890A/5975C, Agilent, USA), and APC (ACQUITY APC, Waters, USA). Prior to FTIR analysis, each sample was mixed with $\mathrm{KBr}$ and pressed into a pellet, from which spectra were recorded over the wavenumber range of $400-4000 \mathrm{~cm}^{-1}$. All samples were analyzed using an Agilent 7890A-5975CGC/MS system equipped with an HP-5MS capillary column (crosslinked $0.5 \%$ phenylmethyl siloxane; $30 \mathrm{~m} \times 0.25 \mathrm{~mm}$ inner diameter; film thickness, $0.25 \mu \mathrm{m}$ ). The electron impact mode ion source temperature was set at $230^{\circ} \mathrm{C}$ with the electron energy set at $70 \mathrm{eV}$, and a quadrupole analyzer was employed with an $\mathrm{m} / \mathrm{z}$ range of 35-500. Data processing was performed using MSD ChemStation software, and compounds were identified by comparing mass spectra with NIST08 library data. The relative content (RC) of each compound was obtained using the peak area normalization method for quantification. APC analysis was performed using three ACQUITY APC XT columns placed in series, with effective molecular weight ranges of 20,000-400,000, 3,000-70,000, and $200-5,000$, respectively. Tetrahydrofuran (THF) was used as the mobile phase at a flow rate of $0.5 \mathrm{~mL} \mathrm{~min}^{-1}$. Prior to analysis, samples $(5 \mathrm{mg})$ were dissolved in THF $(1.5 \mathrm{~mL})$ and the injection volume was set at $10 \mu \mathrm{L}$. These analysis conditions were based on a previously reported procedure [31].

2.4. Physicochemical Properties. The KV values of the specimens were determined at 40 and $100^{\circ} \mathrm{C}$ based on the method GB/T 265/1998 (2004), and the AN of each sample was obtained using the method GB/T7304-2000 (2004). Each measurement was repeated three times to ensure the accuracy of the data. Degradation and oxidation of each of the seven oil samples were evaluated using the Synthetic Turbine Module from the InService Lubricants Analysis Pack in the FTIR software. Spectral ranges of $3595^{-} 3500 \mathrm{~cm}^{-1}$ and $1800^{-} 1670 \mathrm{~cm}^{-1}$ were examined to assess degradation and oxidation, respectively. In each trial, approximately $2.5 \mathrm{~mL}$ of the oil sample was forced through a flow cell using a syringe (taking care to exclude air bubbles) after which spectra were acquired.
2.5. Thermal Stability. The thermal stabilities of the seven oil samples were assessed using a DSC 8000 instrument (PerkinElmer, USA). The initial oxidation temperature (IOT) of each specimen was obtained based on the method QJ/DSH 275-1998. In each trial, an oil sample $(0.6 \mathrm{~mL})$ was transferred into an open aluminum pan that was subsequently sealed. The specimen was then heated from 50 to $300^{\circ} \mathrm{C}$ at $20^{\circ} \mathrm{C} \mathrm{min}^{-1}$ under an oxygen flow rate of $20 \mathrm{~mL} \mathrm{~min}^{-1}$ and oxygen pressure of $3.5 \mathrm{MPa}$. The oxidation induction time (OIT) was determined using the method SH/T 0719-2002. In each experiment, an oil sample $(1.0 \mathrm{~mL})$ was first held at $50^{\circ} \mathrm{C}$, then heated to $220^{\circ} \mathrm{C}$ at $160^{\circ} \mathrm{C} \mathrm{min}^{-1}$ under nitrogen. Subsequently, high-purity oxygen was rapidly passed into the heating chamber until the oxygen pressure reached $3.5 \mathrm{MPa}$, after which oxygen flow was kept constant at $20 \mathrm{~mL} \mathrm{~min}^{-1}$.

\section{Results and Discussion}

\subsection{Chemical Characterization of Oil Samples}

3.1.1. FTIR Analysis. In complex molecules, functional groups are typically the most important structural components [32]. FTIR spectroscopy is helpful in this regard, having been used for many years to determine the distribution of functional groups in lubricating oils [33]. The FTIR spectra of the seven oil samples following various TT processes were found to be similar, with few changes after heating. Therefore, only the spectra of $\mathrm{DE}_{\mathrm{r}}$, $\mathrm{DE}_{230}$, and $\mathrm{DE}_{300}$ are provided in Figure 1. These spectra exhibited peaks attributed to $-\mathrm{CH}_{3}$ and $-\mathrm{CH}_{2}-(2959,2930$, and $\left.2859 \mathrm{~cm}^{-1}\right),-\mathrm{CH}_{2^{-}}\left(1464 \mathrm{~cm}^{-1}\right)$, and $-\left(\mathrm{CH}_{2}\right)_{\mathrm{n}^{-}}\left(727 \mathrm{~cm}^{-1}\right)$ groups, indicating that these samples contained long-chain alkanes. Peaks attributed to $\mathrm{C}=\mathrm{O}\left(1737 \mathrm{~cm}^{-1}\right)$ and $\mathrm{C}-\mathrm{O}-\mathrm{C}$ $\left(1174 \mathrm{~cm}^{-1}\right)$ groups were also present, confirming the presence of fatty acid esters. The $\mathrm{N}-\mathrm{H}$ stretching vibration at $3463 \mathrm{~cm}^{-1}$, $\mathrm{N}-\mathrm{H}$ deformation vibration at $1591 \mathrm{~cm}^{-1}$, and C-N stretching vibration at $1355 \mathrm{~cm}^{-1}$ all confirmed that the samples contained amine antioxidants, while the peak at $1241 \mathrm{~cm}^{-1}$ further indicated that these were aromatic secondary amines. The peaks present at 3544,1097, and $1013 \mathrm{~cm}^{-1}$ suggested the presence of alcohols, and the peak at $1420 \mathrm{~cm}^{-1}$ was attributed to phenyl-P moieties. As increasing the temperature did not significantly affect these functional groups, the ester, amine, and alcohol functional groups were evidently unaffected by heating.

3.1.2. GC-MS Analysis. As shown in Figures 2(a)-2(c) and Table 1, a total of 53 organic compounds were detected in the seven oil samples. These included six hydrocarbons (HCs), one alcohol, 20 esters (10 monoesters, eight diesters, one triester, and one carbonate), 17 additives and additive derivatives (ADs), and nine other compounds (OCs). A total of $32,35,35,35$, and 36 compounds were found in the series of samples from $\mathrm{DE}_{\mathrm{r}}$ to $\mathrm{DE}_{250}$, respectively, with minimal variation in the types and amounts of these compounds below $250^{\circ} \mathrm{C}$. In contrast, at 270 and $300^{\circ} \mathrm{C}, 42$ and 48 compounds were detected in $\mathrm{DE}_{270}$, respectively. Total ion chromatograms (Figure 2(b)) showed significant variation in compounds prior to heating for $12 \mathrm{~min}$, with hydrocarbons and monoesters comprising the majority of 


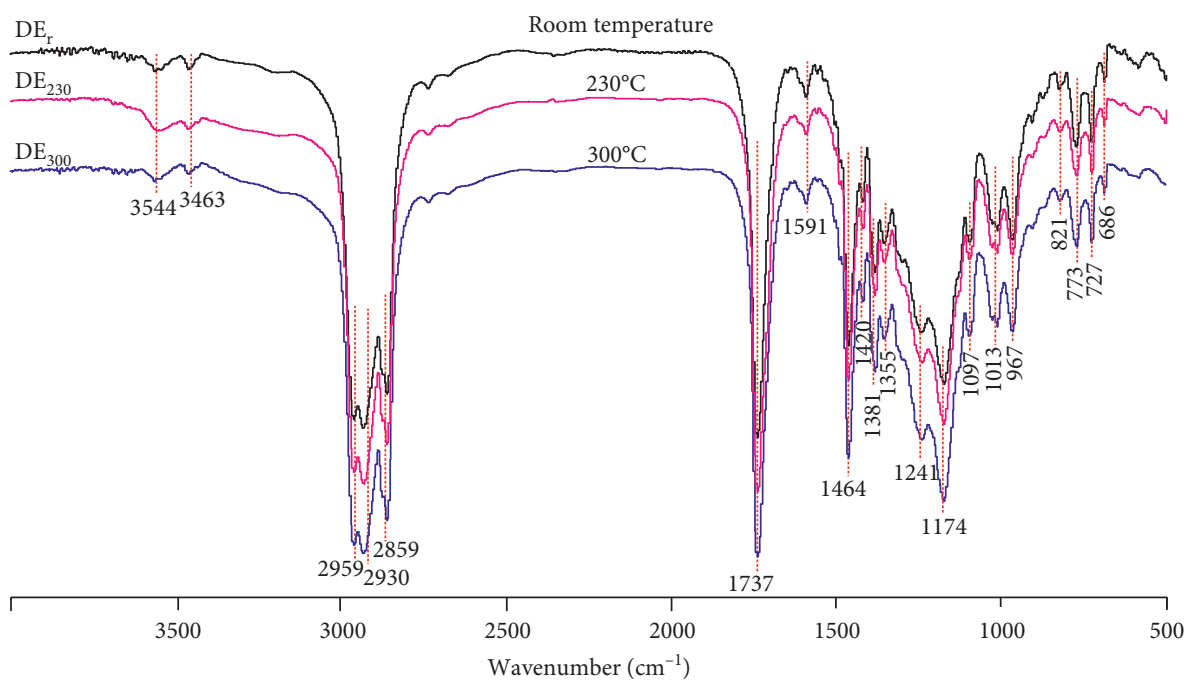

FIgURE 1: FTIR spectra of $\mathrm{DE}_{\mathrm{r}}, \mathrm{DE}_{230}$, and $\mathrm{DE}_{300}$ samples.

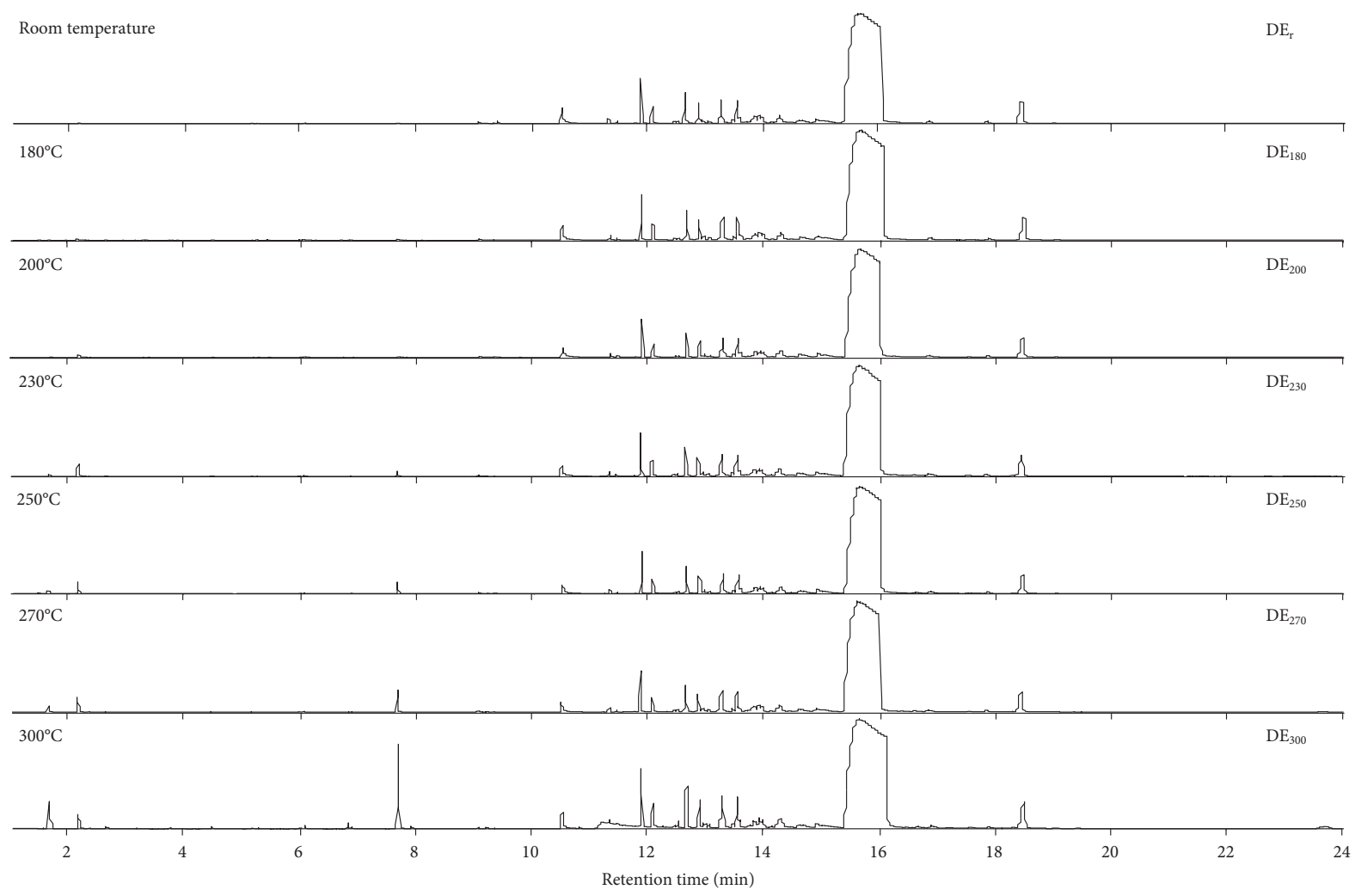

(a)

FIgURE 2: Continued. 


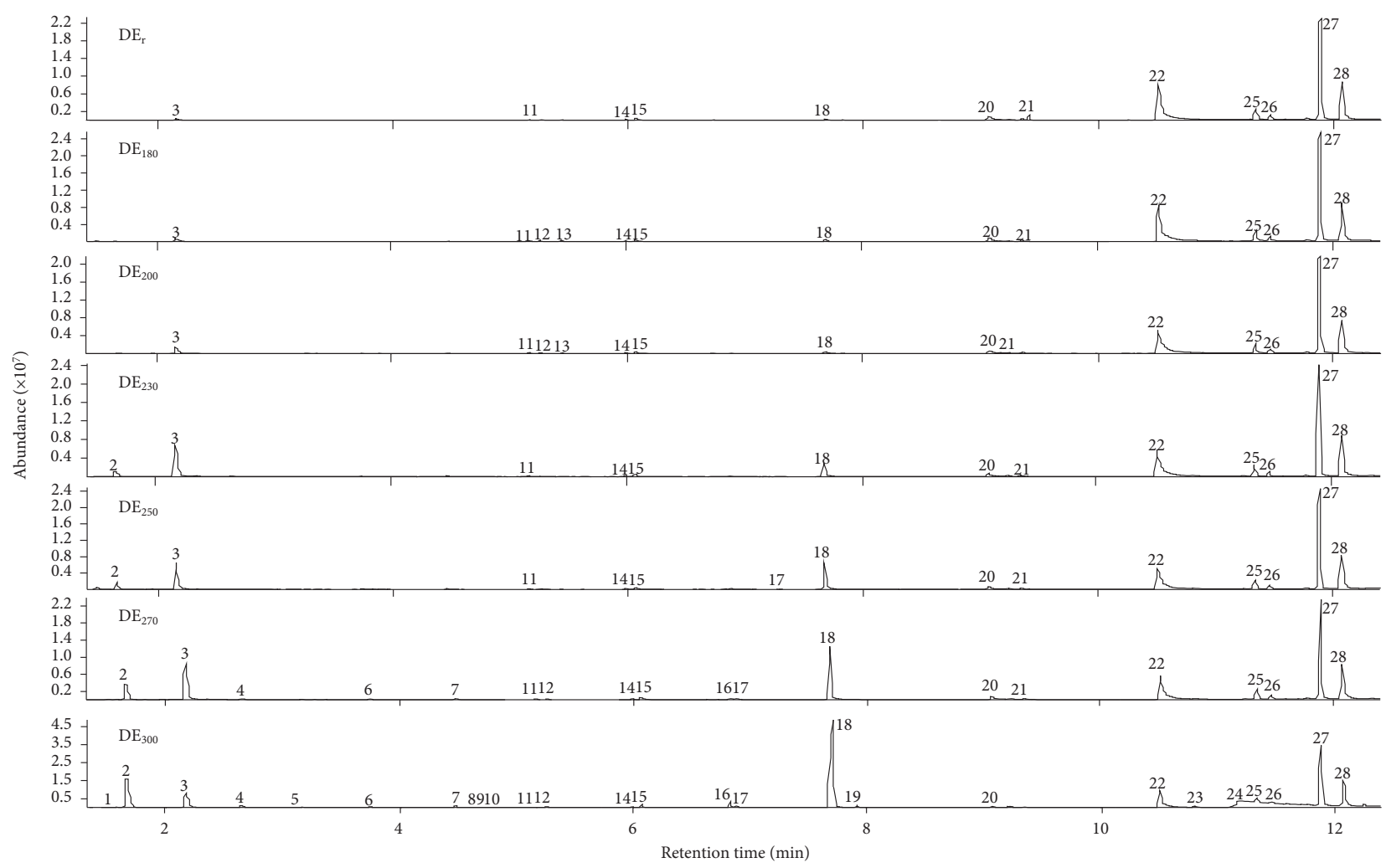

(b)

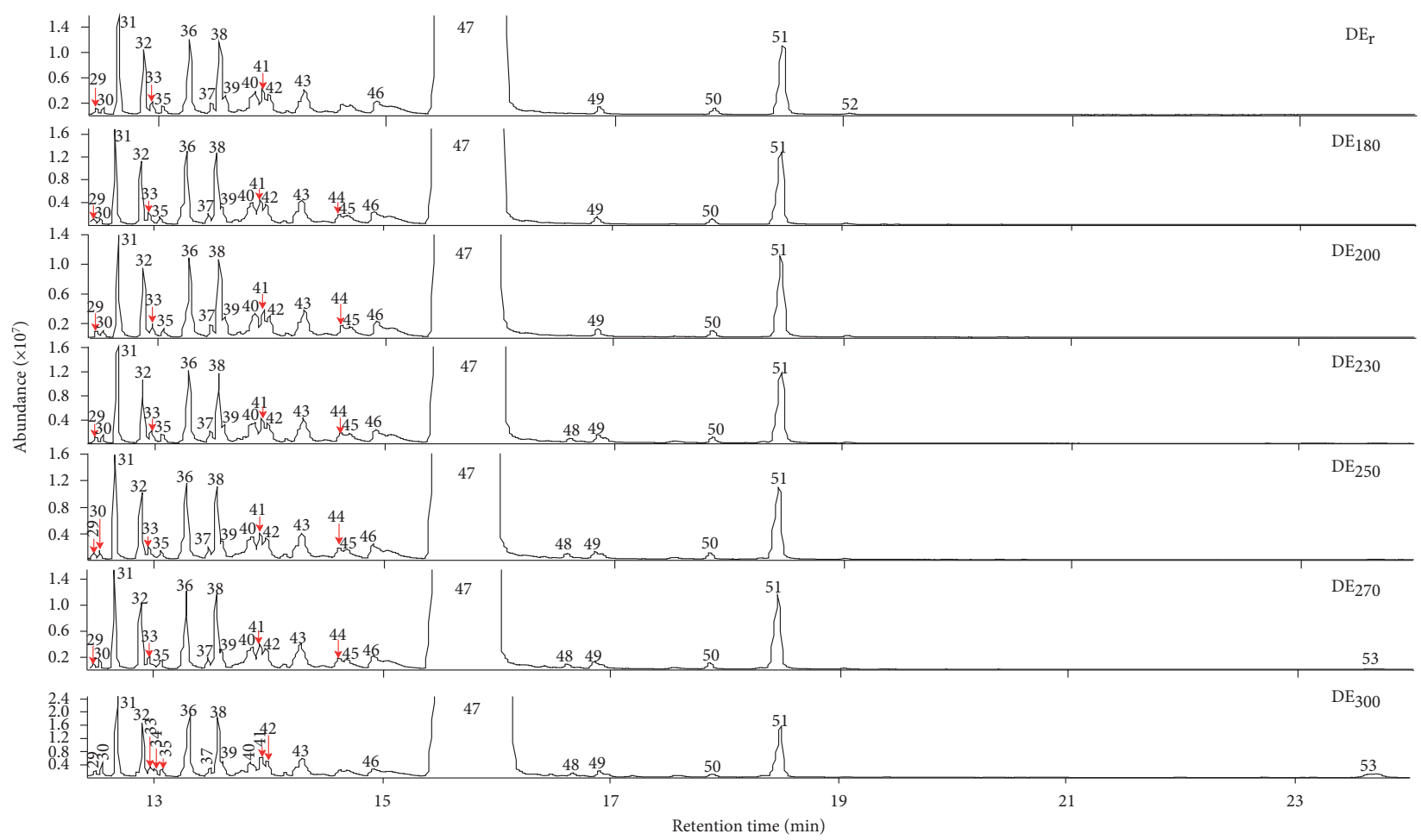

(c)

Figure 2: (a) Total ion chromatograms of oil samples after heating at different temperatures. (b) Total ion chromatograms of various oil samples over a retention time range of 1.4-12.4 min. (c) Total ion chromatograms of oil samples over a retention time range of 12.6-24.0 min. 


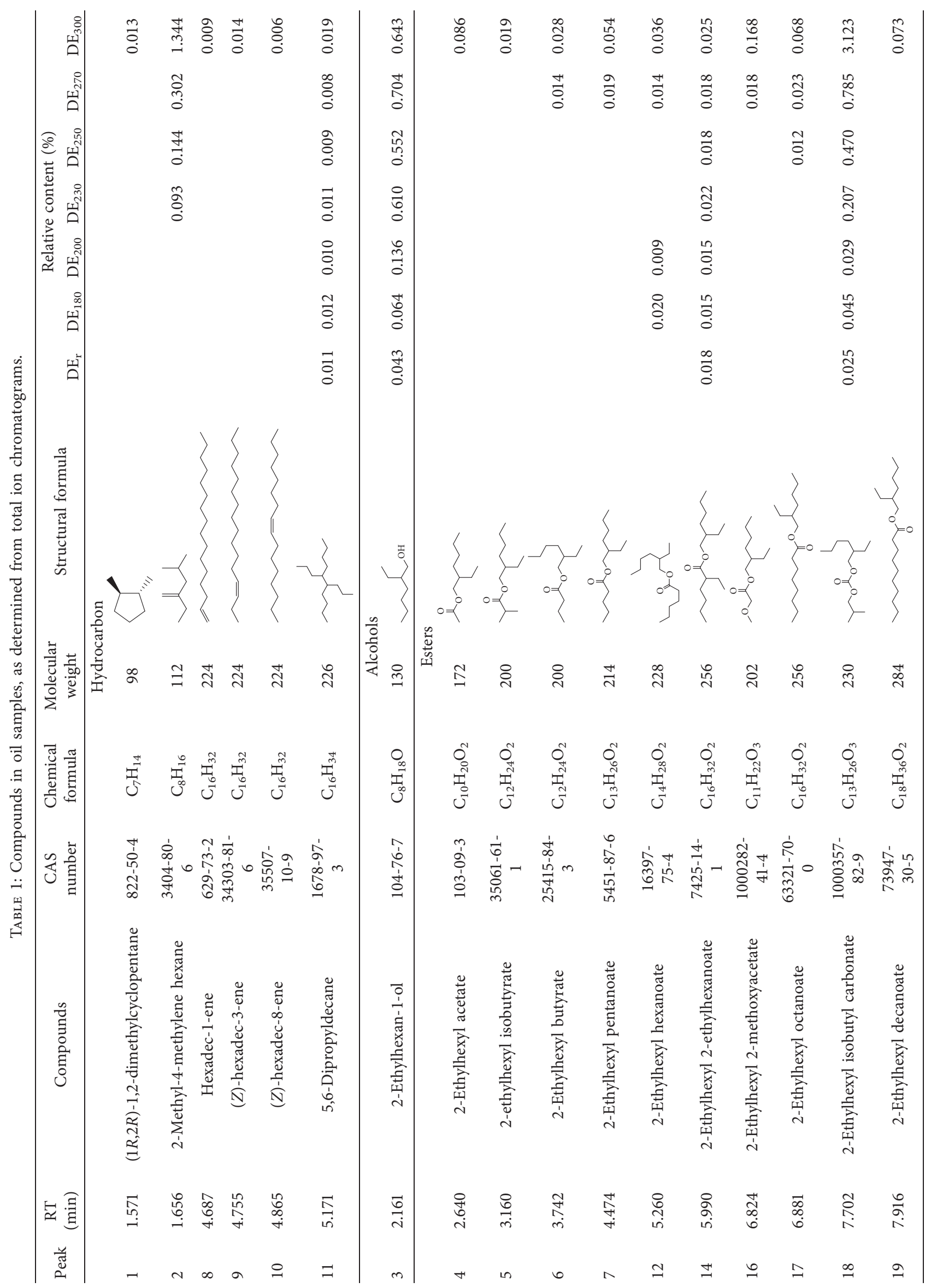




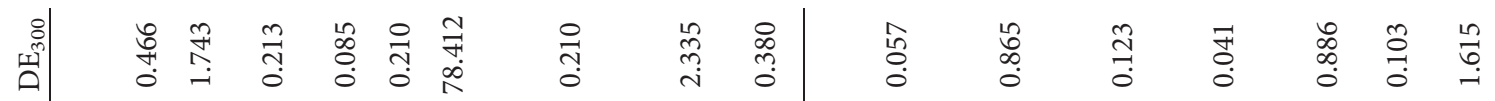

毵

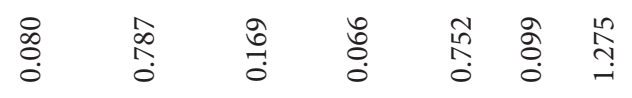

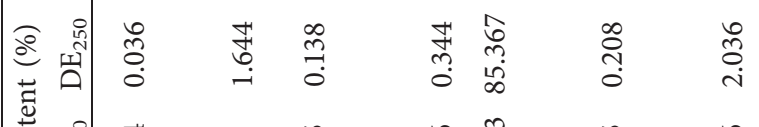

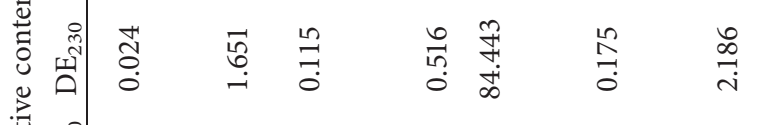

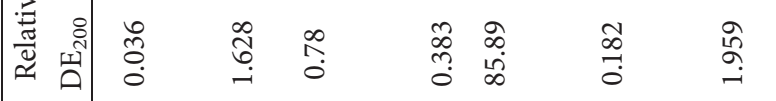

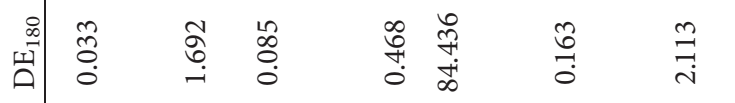

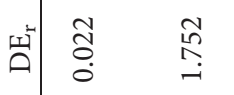

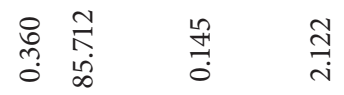

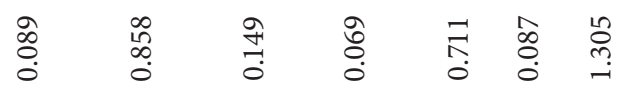

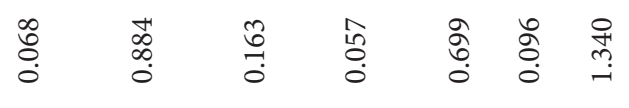

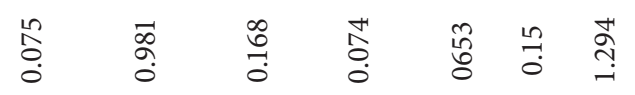

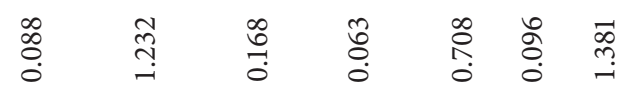

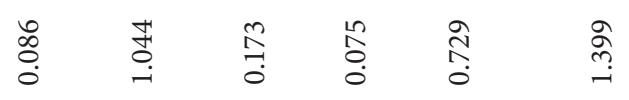

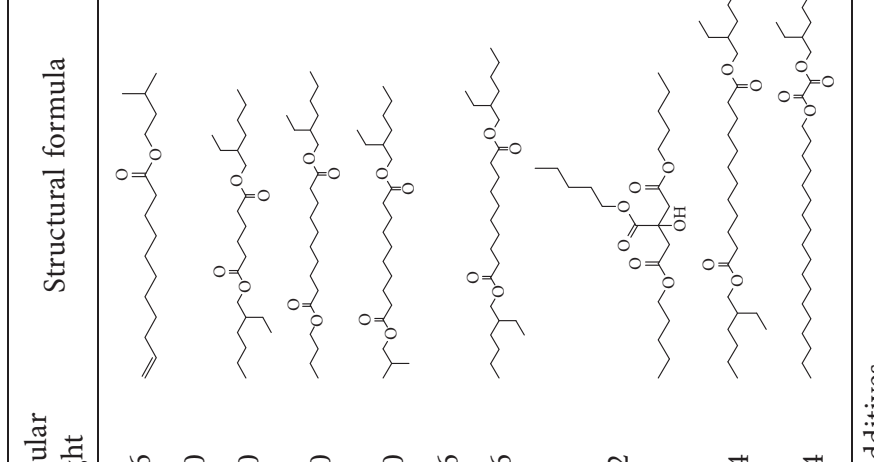

$\sum_{0}$

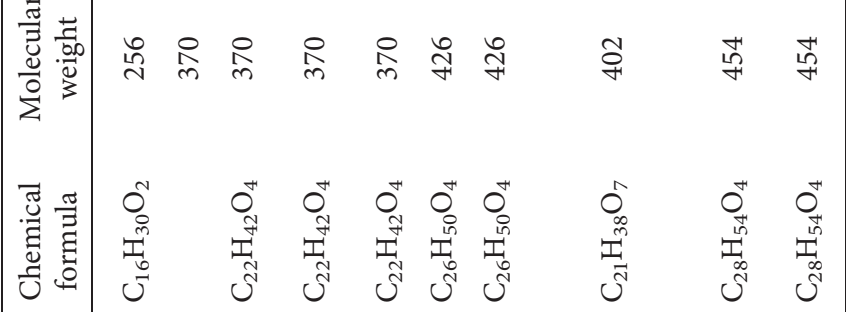

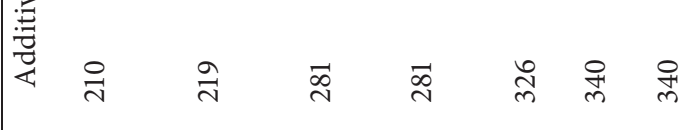

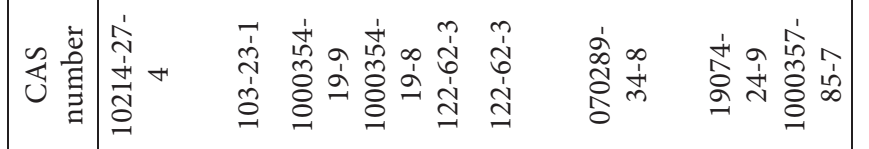

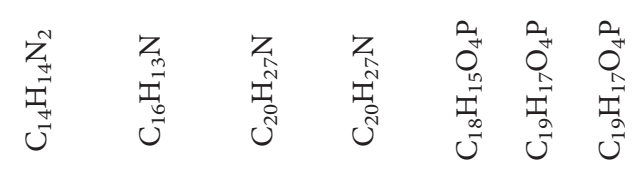

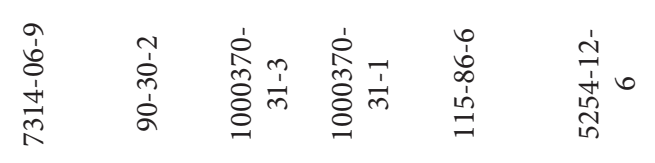

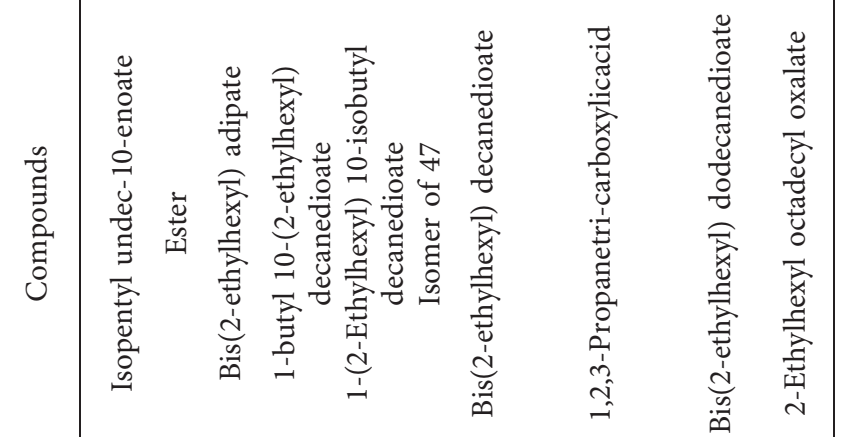

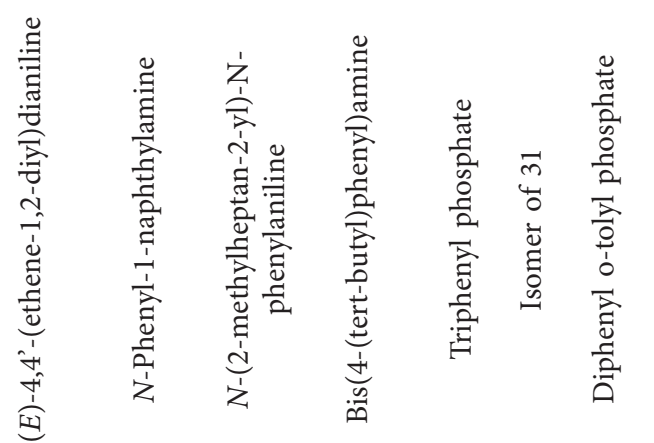

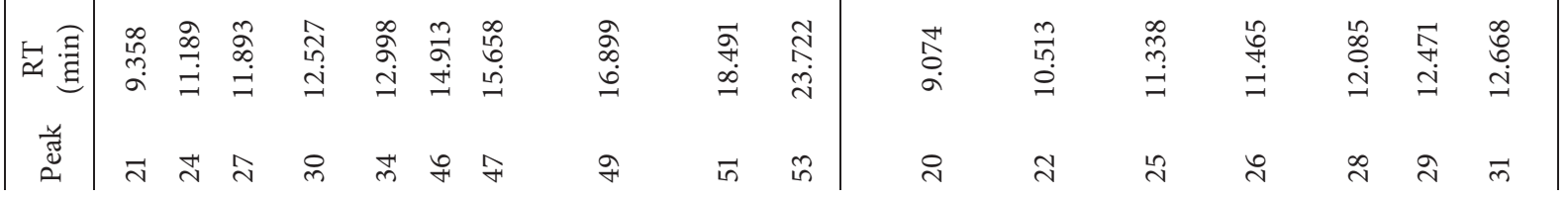




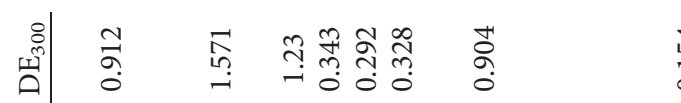

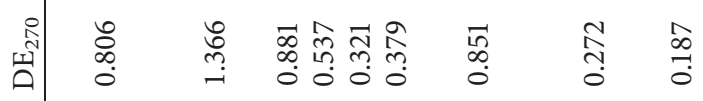

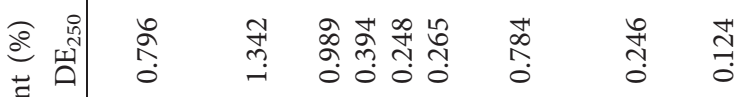

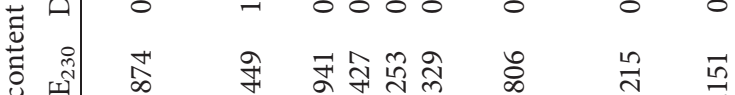

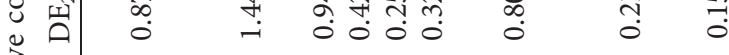

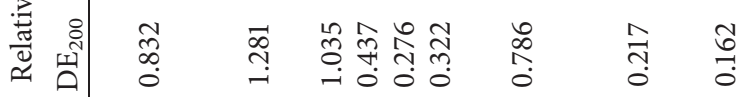

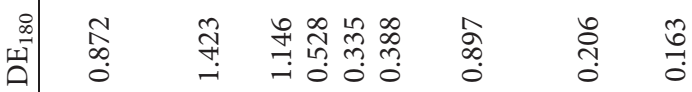

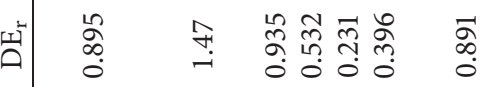

递

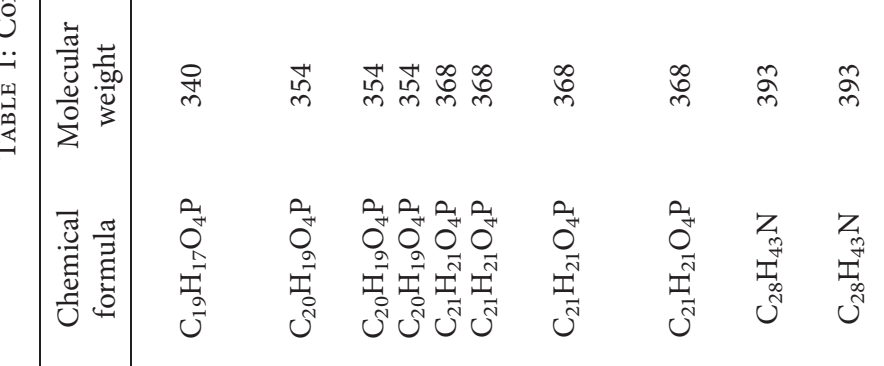

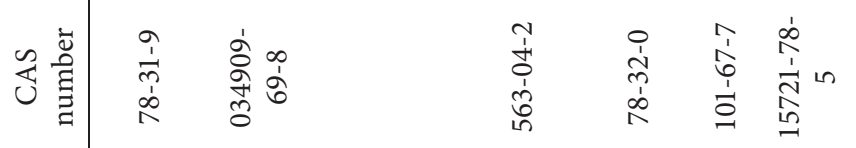

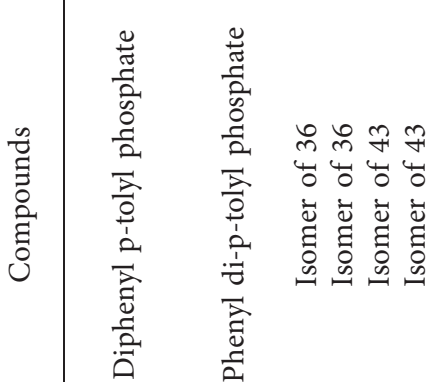

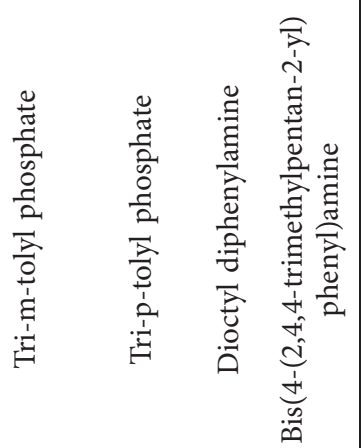

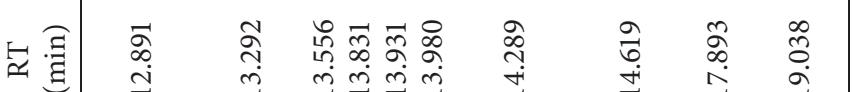
节

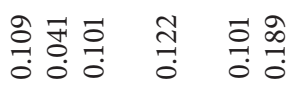

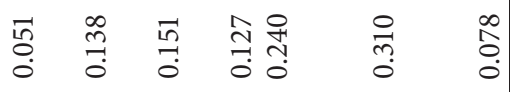

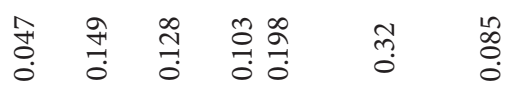

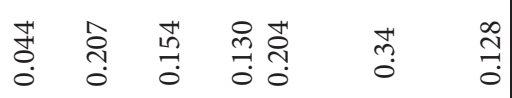

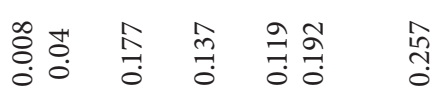

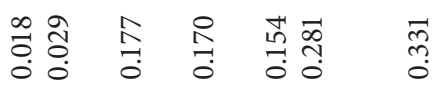

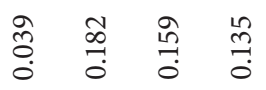

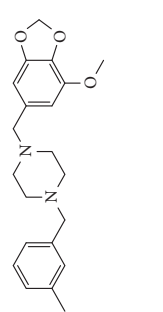

竞

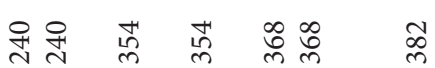

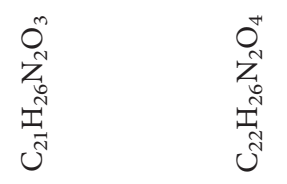

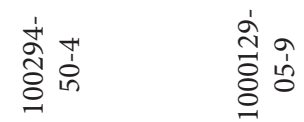

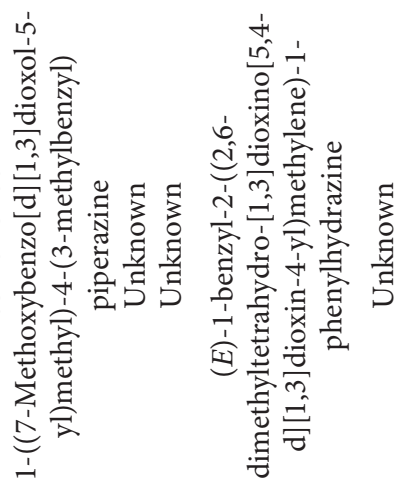

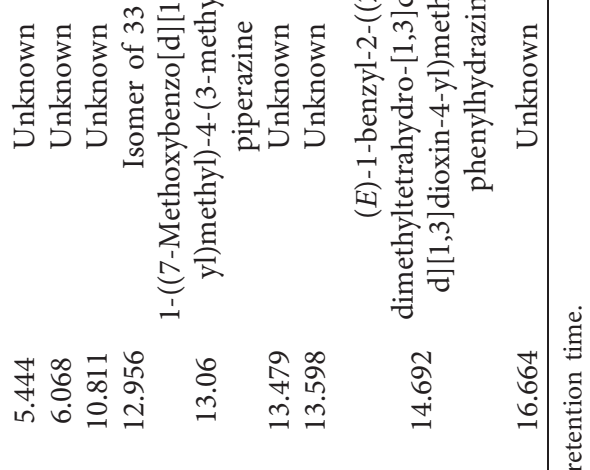

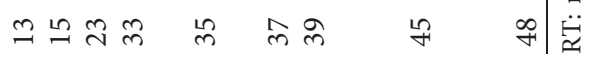


these species. Overall, the data showed that these DEALO samples were highly resistant to thermal oxidation and exhibited minimal evaporation.

Table 1 indicates that hydrocarbons in the oils ranged from $\mathrm{C}_{7}$ to $\mathrm{C}_{16}$, including one cycloalkane, four olefins, and one isoparaffin. Dimethyl cyclopentane (1) and three hexadecene isomers $(\mathbf{8}-\mathbf{1 0})$ were detected only in $\mathrm{DE}_{300}$, while 2-methyl-4 methylene hexane (2) was found in samples $\mathrm{DE}_{230}-\mathrm{DE}_{300}$ after heating above $230^{\circ} \mathrm{C}$. As the temperature was increased, compound variation and $\mathrm{RC}$ values also increased. A total of six different species were eventually identified and the RCs of the hydrocarbons increased to $1.40 \%$ for $\mathrm{DE}_{300}$. A total of 20 different esters, ranging from $\mathrm{C}_{10}$ to $\mathrm{C}_{28}$, were found in the seven samples, including ten monoesters, eight diesters, one carbonate, and one triesters. The number of different esters found in $\mathrm{DE}_{\mathrm{r}}, \mathrm{DE}_{180}, \mathrm{DE}_{200}$, $\mathrm{DE}_{230}, \mathrm{DE}_{250}, \mathrm{DE}_{270}$, and $\mathrm{DE}_{300}$ was $8,10,10,9,10,15$, and 19 , respectively. Few changes in these esters were observed below $270^{\circ} \mathrm{C}$, but further variation occurred above this temperature, suggesting fragmentation of the long-chain base oils. The variety of monoesters also increased above $270^{\circ} \mathrm{C}$. $\mathrm{C}_{10}-\mathrm{C}_{13}(4-7)$ and $\mathrm{C}_{18}$ monoesters (19), as well as 2ethylhexyl 2-methoxyacetate (16), were only detected following heating above $270^{\circ} \mathrm{C}$. The monoester/diester ratios were $2: 5,4: 5,4: 5,3: 5,4: 5,7: 6$, and $9: 8$ in $\mathrm{DE}_{\mathrm{r}}, \mathrm{DE}_{180}$, $\mathrm{DE}_{200}, \mathrm{DE}_{230}, \mathrm{DE}_{250}, \mathrm{DE}_{270}$, and $\mathrm{DE}_{300}$, respectively.

The same esters showed varying RCs for different oil samples. Specifically, the RC of 2-ethylhexyl isobutyl carbonate (18) increased across the $\mathrm{DE}_{\mathrm{r}}-\mathrm{DE}_{300}$ series, and the $\mathrm{RC}$ values for 1-butyl 10-(2-ethylhexyl)decanedioate (30) also increased with increasing temperature above $230^{\circ} \mathrm{C}$. However, the RC for base oil BEHDD (47) varied only slightly below $270^{\circ} \mathrm{C}$, with values of $85.712,84.436,85.890,84.443,85.367$, and $83.533 \%$, respectively. Increasing the temperature to $300^{\circ} \mathrm{C}$ reduced the $\mathrm{RC}$ for $\mathrm{BEHDD}$ to $78.412 \%$. The only alcohol detected was 2-ethylhexan-1-ol (3), with an RC of less than $0.136 \%$ below $230^{\circ} \mathrm{C}$, which continually increased to above $0.552 \%$ at temperatures in excess of $230^{\circ} \mathrm{C}$.

The additives found included two amine antioxidants ( $N$-phenyl-1-naphthylamine (22) and dioctyldiphenylamine (50)) and one antiwear agent (tri-o-tolyl phosphate (43)), as well as derivatives of these compounds generated during storage and use. Minimal changes occurred in the RCs of these compounds with heating. As summarized in Table 1, dioctyldiphenylamine (50) in the oils generated $N$-(2-methylheptan-2-yl)- $N$-phenylaniline (25) and bis(4(tert-butyl)phenyl)amine (26), while triphenyl phosphate (28), diphenyl tolyl phosphate $(29,31,32)$, and phenyl ditolyl phosphate $(36,38,40)$ were produced from tri-otolyl phosphate. It was reasonably inferred that the antioxidants and antiwear agents were all unstable, even under storage conditions. Chromophoric and/or auxochromic compounds were also generated from the degradation of these additives, such that the oil samples became dark brown or even black after heating at high temperatures $[34,35]$. The oils also contained several compounds appearing at different temperatures that could not be identified but were not obviously affected by temperature.
3.1.3. APC Analysis. As shown by the data for the seven oil samples in Figure 3, the number-average molecular weight $\left(M_{n}\right)$ and weight-average molecular weight $\left(\mathrm{M}_{\mathrm{w}}\right)$ remained relatively stable. The $M_{n}$ and $M_{w}$ of $D_{r}$ were 547 and 533, while those of $\mathrm{DE}_{180}$ and $\mathrm{DE}_{200}$ were reduced to 538 and 542, and 537 and 542, respectively. The $M_{n}$ and $M_{w}$ increased to 550 and 556 for $\mathrm{DE}_{230}$, with similar values of 549 and 554,549 and 554, and 550 and 555 obtained for $\mathrm{DE}_{250}-\mathrm{DE}_{300}$ series, respectively. The $\mathrm{M}_{\mathrm{w}}$ is typically reduced by cleavage reactions and increased by polymerization. According to GC/MS analysis, the number of compounds detected increased from 32 in $\mathrm{DE}_{\mathrm{r}}$ to 35 in $\mathrm{DE}_{180}$ and $\mathrm{DE}_{200}$. The APC data showed that the $\mathrm{M}_{\mathrm{w}}$ values of $\mathrm{DE}_{180}$ and $\mathrm{DE}_{200}$ decreased by about $10 \mathrm{Da}$, indicating that these oils underwent minimal degradation. Increasing the temperature to $230^{\circ} \mathrm{C}$ generated 36 compounds. The APC results also showed that the $\mathrm{M}_{\mathrm{w}}$ of $\mathrm{DE}_{230}$ was nearly $20 \mathrm{Da}$ higher than that of $\mathrm{DE}_{200}$. Therefore, polymerization reactions were likely promoted with increasing temperature, with the rate of polymerization exceeding the rate of bond cleavage. GC-MS analysis identified 2ethylhexyloctadecyloxalate (53) following heating at 270 and $300^{\circ} \mathrm{C}$, with a molecular weight of 454 . The present GC-MS analysis was only able to detect volatile nonpolar or weakly polar compounds with molecular weights of less than $500 \mathrm{Da}$, such that the majority of polymers could not be detected. However, the APC results confirmed that polymerization occurred in these oil samples as the temperature increased. As these polymers were able to almost completely dissolve in the oil, there was almost no change in the molecular weight, even at $300^{\circ} \mathrm{C}$.

\subsection{Physicochemical Properties of Oil Samples}

3.2.1. Viscosity and Acid Number. Viscosity is among the most basic physical properties of a lubricating oil. This property is related to the internal friction coefficient of the fluid and directly affects the lubricating characteristics of the oil [36]. As shown in Figure 4, the KV values of the DEALO specimens at 40 and $100^{\circ} \mathrm{C}\left(\nu_{40}\right.$ and $\left.\nu_{100}\right)$ were 11.17 and $3.24 \mathrm{~mm}^{2} \mathrm{~s}^{-1}$, respectively, and no obvious changes were observed after heating. The viscosity index (VI) represents the degree of change in viscosity with temperature for a fluid $[37,38]$. The VI for the fresh oil sample was determined to be 168.53 , which is typical for a very high grade material. With increasing temperature, the VI initially decreased, then increased, and finally decreased again. Small molecular compounds (SMCs) were concluded to be present at higher concentrations than high-molecular-weight compounds (HMWCs) below $200^{\circ} \mathrm{C}$ owing to some pyrolysis. Therefore, the VI values of $\mathrm{DE}_{180}$ and $\mathrm{DE}_{200}$ were lower than that of $\mathrm{DE}_{\mathrm{r}}$. As the temperature was continually increased, WMCs were generated as a result of thermal oxidation processes $[39,40]$, although the oil viscosity did not significantly increase [39, 41, 42]. The GC-MS data indicated that various SMCs, including HCs, alcohols, monoesters, and other compounds, also appeared at high temperatures. Simultaneously, the antioxidants and antiwear agents were decomposed into these SMCs, which negatively affected the viscosity-temperature characteristics of the oils [16]. The VI values of the oil samples exhibited less variation at relatively high temperatures, with 


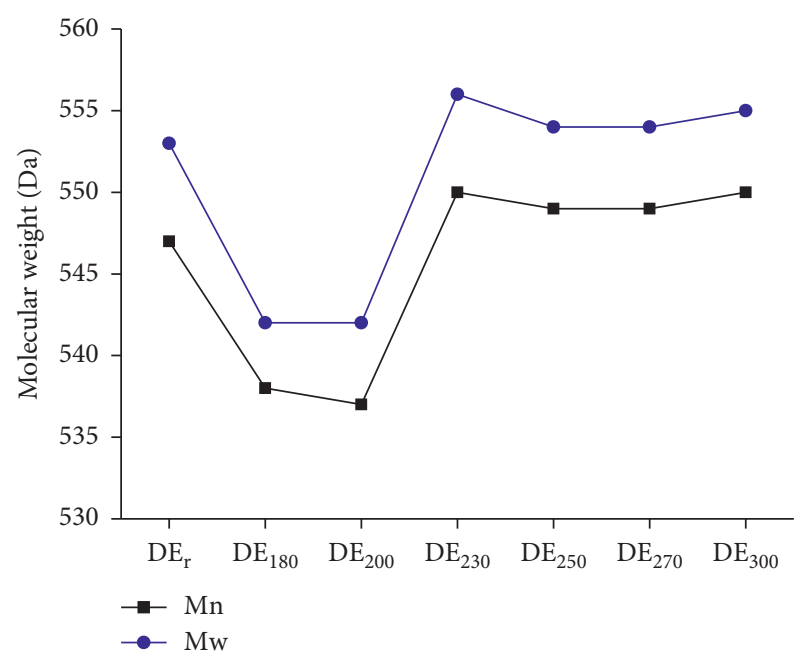

FIgURE 3: Molecular weights of oil samples.

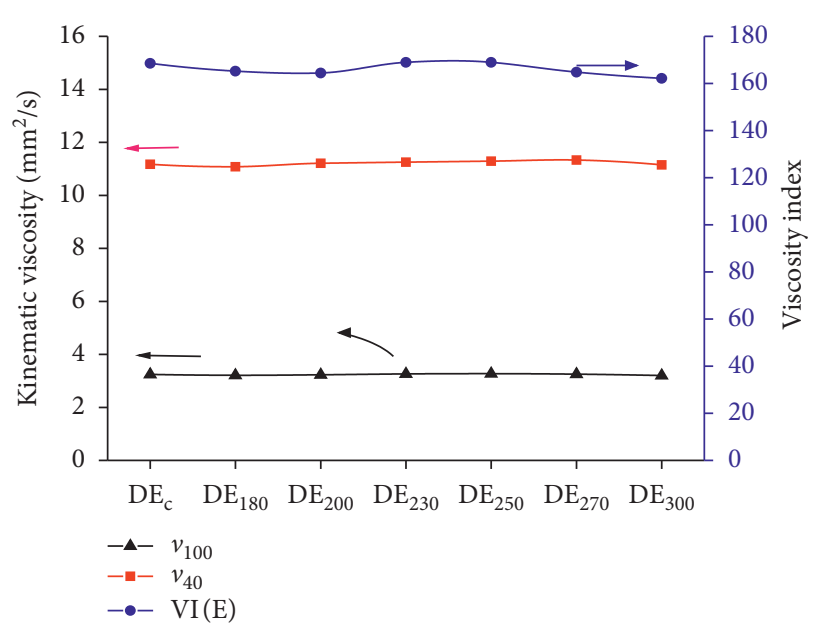

Figure 4: $v_{40}, v_{100}$, and viscosity index values of oil samples.

values ranging from 168.93 to 162.13 . Overall, these data show that this DEALO was close to being an ideal lubricating oil $[43,44]$ suitable for use in aeroengines.

In contrast to the viscosity values, the $\mathrm{AN}$ of each oil sample changed dramatically with heating at different temperatures. As shown in Figure 5, no large variations in AN were observed below $230^{\circ} \mathrm{C}$, with values of $0.14,0.19$, and $0.24 \mathrm{mg}$ $\mathrm{KOH} \mathrm{g}{ }^{-1}$ for samples $\mathrm{DE}_{\mathrm{r}}-\mathrm{DE}_{200}$, respectively. However, the $\mathrm{AN}$ value was increased to $0.77 \mathrm{mg} \mathrm{KOH} \mathrm{g}^{-1}$ in $\mathrm{DE}_{230}$, which exceeded the typical useable upper limit of $0.5 \mathrm{mg} \mathrm{KOH} \mathrm{g}^{-1}$. As the temperature was further increased, the AN values also increased, at 1.07, 2.15, and $10.62 \mathrm{mg} \mathrm{KOH} \mathrm{g}^{-1}$ for $\mathrm{DE}_{250}$, $\mathrm{DE}_{270}$, and $\mathrm{DE}_{300}$, respectively, all of which greatly exceeded the normal useable range. Acidic compounds in such oils are primarily generated from decomposition of the base oils and additives [45]. Specifically, acidic colloids are produced by oxidation of the base oils, and extreme pressure antiwear agents and rust inhibitors that contain phosphorus or sulfur can readily form acids. The present DEALOs were primarily composed of BEHDD, amine antioxidants (n-phenyl-1naphthylamine and dioctyldiphenylamine), and an antiwear

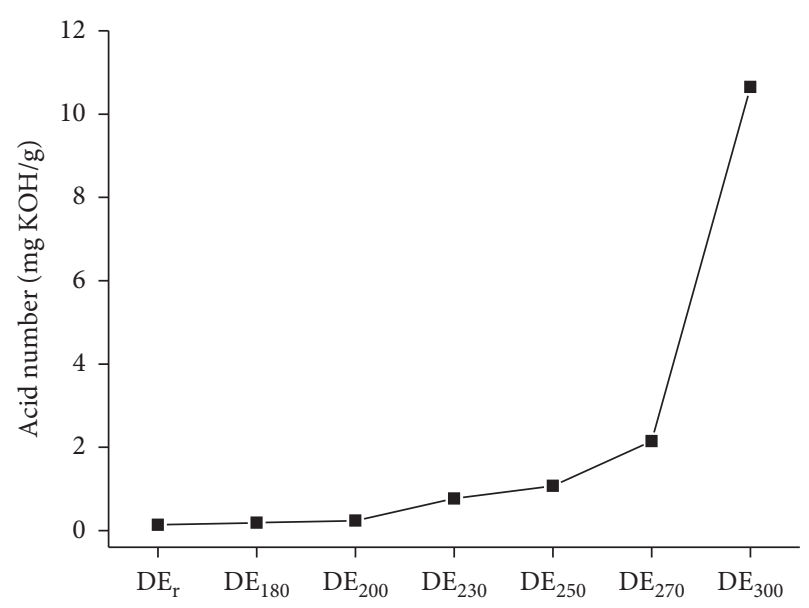

Figure 5: AN values of oil samples.

agent (tri-o-tolylphosphate). The terminal alcohol group in diisoxide sebacate has an active hydrogen because hydrogens bonded to $\beta$-carbons are prone to thermal decomposition to produce six-membered cyclic intermediates that decompose to acids and alkenes [46]. Olefins in the oils were identified during GC/MS analysis (8-10), and the formation of these compounds was attributed to cracking, which also generated alcohols, aldehydes, and carboxylic acids by reactions with oxygen. An alcohol (3), a carbonate (16), low-molecular-weight monoesters, and some unknown compounds containing carbonyl groups $(\mathbf{1 3 , 1 5 )}$ were also identified. Decomposition of the antioxidants and antiwear agent to form acidic derivatives at high temperatures would be expected to greatly increase the AN of the oil samples. When this value is increased sufficiently, the oil will begin to corrode metal parts and shorten the service life of the machine in which it is used. Furthermore, highmolecular-weight polymers will form a sludge, while cracking will generate low-molecular-weight acids that are highly soluble in the oil owing to the excellent solubility of esters. Consequently, the AN can increase by several orders of magnitude $[47,48]$. The formation of these acidic compounds will also increase the polarity of the oil [49]. Polar compounds can improve the strength of oil films and, therefore, enhance the lubrication ability of the oil $[16,50]$, although such films can also be disrupted at elevated temperatures and high engine loads. For these reasons, DEALOs provide superior lubrication in the operational temperature range of ${ }^{-} 60$ to $200^{\circ} \mathrm{C}$.

3.2.2. Oxidation Value and Degradation Products. As shown in Figure 6, higher temperatures promoted both degradation and oxidation. The degradation values determined for the $\mathrm{DE}_{\mathrm{r}}-\mathrm{DE}_{300}$ series from FTIR analysis were 4.78, 5.46, 7.39, $9.87,12.91,16.19$, and 20.22, respectively. Therefore, the extent of degradation was concluded to be limited below $230^{\circ} \mathrm{C}$ but sharply increase above this temperature. This trend was similar to that exhibited by the AN data. The oxidation values increased relatively slowly below $270^{\circ} \mathrm{C}$ but increased more steeply from $\mathrm{DE}_{270}$ to $\mathrm{DE}_{300}$. These data confirmed that oxidation reactions occurred to a significant extent at high temperatures. Both the oxidation and 
pyrolysis reactions of ester-based oils can occur at such temperatures, and the main products (carbonyl-containing compounds such as acids, monoesters, and aldehydes) can further increase the acidity of the oil and promote the degradation of additives.

3.3. Thermal Stability of Oil Samples. The high-temperature oxidation stability (HTOS) of an ALO refers to its ability to resist oxidation and degradation at elevated temperatures. HTOS is not only an important indicator of performance but also a key parameter that determines the maximum operating temperature of the oil. Therefore, a detailed investigation of the HTOS is crucial to improve the oil quality and select the optimal oil for a given application. PDSC assesses the oxidation of a thin film of oil, simulating the oxidation of lubricating oils under working conditions [51]. This technique can evaluate the oxidative stability of lubricating base oils and performance of antioxidants and has the advantages of being fast, accurate, and reproducible. In PDSC, IOT and OIT are determined using temperature-programmed and constanttemperature methods. Higher IOT and OIT values reflect better oxidation resistance in an oil. In the present work, a constant temperature of $210^{\circ} \mathrm{C}$ was applied during OIT analysis. Assessing the TOS of aviation oils is important, but challenging [52]. As shown in Figure 7, the IOT for $\mathrm{DE}_{\mathrm{r}}$ was found to be $254.69^{\circ} \mathrm{C}$, with an inflection point at this temperature followed by a significant decline. The IOT for $\mathrm{DE}_{300}$ was much lower, at $243.37^{\circ} \mathrm{C}$. An OIT was observed at $210^{\circ} \mathrm{C}$ with an inflection point at $250^{\circ} \mathrm{C}$, such that the OIT of $\mathrm{DE}_{300}$ was only $17.11^{\circ} \mathrm{C}$. Overall, the TOS values for the DEALOs were better below $250^{\circ} \mathrm{C}$, although these oils continue to be used as the main lubricating oils for aeroengines at present.

3.4. Possible Degradation Mechanism. The TOS values of DEALO samples were evidently affected by the molecular structure of the ester. The activation energy will also be different for different compounds, and the deterioration mechanism will vary at high temperatures $[53,54]$. The TOS of BEHDD is largely determined by the reactivity of the hydrogen atom on the $\beta$-carbon of the alcohol group. This hydrogen can combine with a carbonyl oxygen atom in the ester to form an intramolecular hydrogen bond and generate a six-membered ring structure. When heated, the $\mathrm{C}-\mathrm{H}$ bond at the $\beta$-position breaks, producing olefins and carboxylic acids that are corrosive to metals (Figure 8).

The thermal oxidation of esters is believed to typically proceed via a free radical chain reaction initiated by light or heat and catalyzed by metals, involving initiation, propagation, and termination. As shown in Figure 9, the oxidation of lubricating oils eventually generates ketones and aldehydes, which form sludge and other deposits that limit the service life of the oil and reduce its high-temperature performance [55]. Adding antioxidants to lubricating oils can be beneficial, and the two antioxidants used in this study were arylamine antioxidants (AAAXs) with excellent high temperature antioxidation properties. AAAXs act as free radical scavengers [56] by combining with free radicals to eliminate them. The present experiments were performed

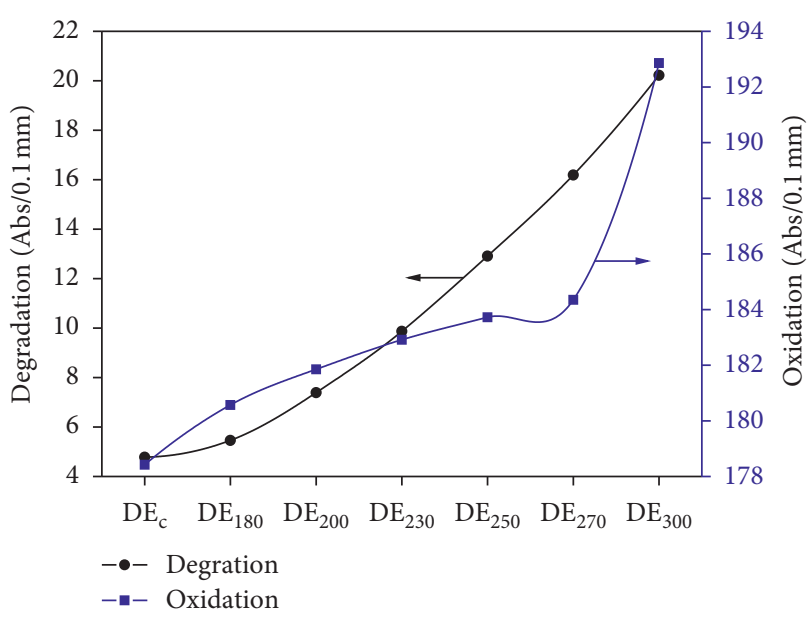

Figure 6: Degradation and oxidation of oil samples.

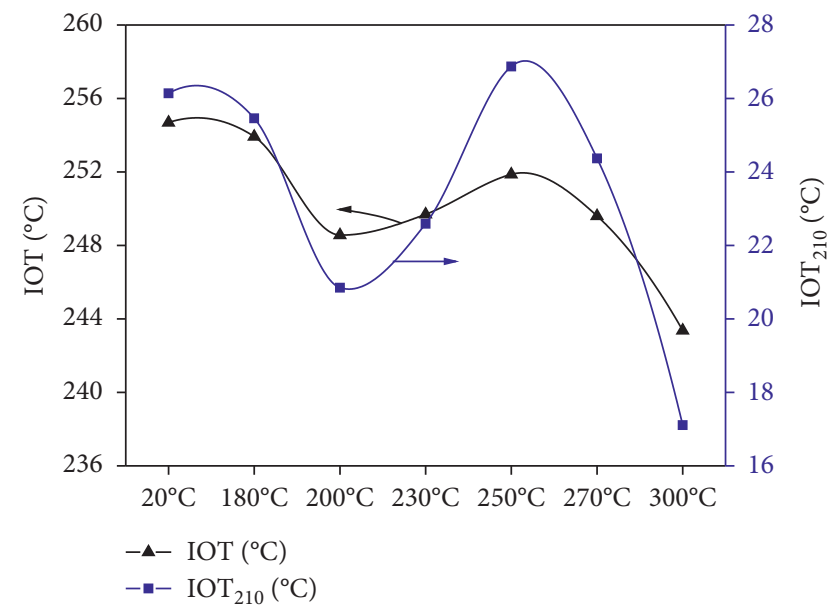

Figure 7: IOT and OIT values of oil samples.

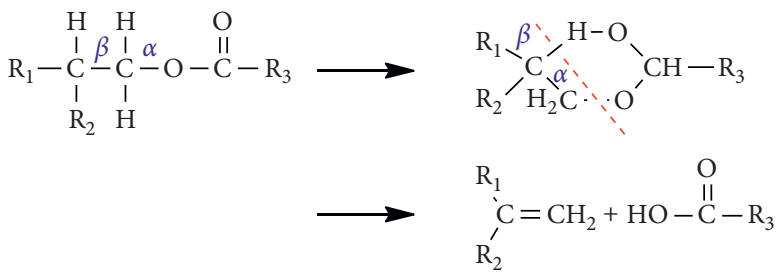

FIgURE 8: Thermal pyrolysis mechanism of diesters.

with some exposure to air, but few thermal oxidation products were detected by GC-MS. Pyrolysis is suggested to be the main thermal degradation mechanism of BEHDD, such that pyrolysis and cleavage of $\beta-\mathrm{C}-\mathrm{H}$ and $\mathrm{C}-\mathrm{C}$ bonds primarily occur (Figure 10) $[16,26,57]$.

As shown in Figure 10(a), BEHDD can be hydrolyzed at high temperatures. The $\mathrm{C}-\mathrm{O}$ ester bond is preferentially cleaved to generate products such as 2-ethylhexan-1-ol (3) and 2-ethylhexyl-10-oxodecanoate, which can be further oxidized to the more stable 10-((2-ethylhexyl)oxy)-10-oxodecanoic acid. Thermal cleavage can also occur at the $\mathrm{C}_{2}-\mathrm{C}_{3}$ bond in the alcohol chain, generating 1-butyl-10-(2-ethylhexyl) 


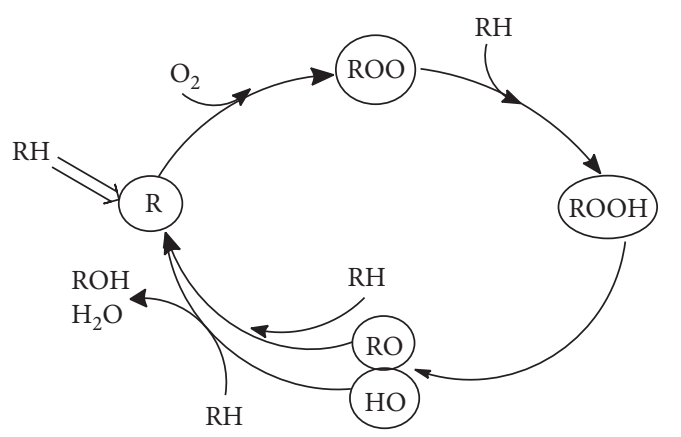

FIGURE 9: Oxidation process scheme for lubricating oils.

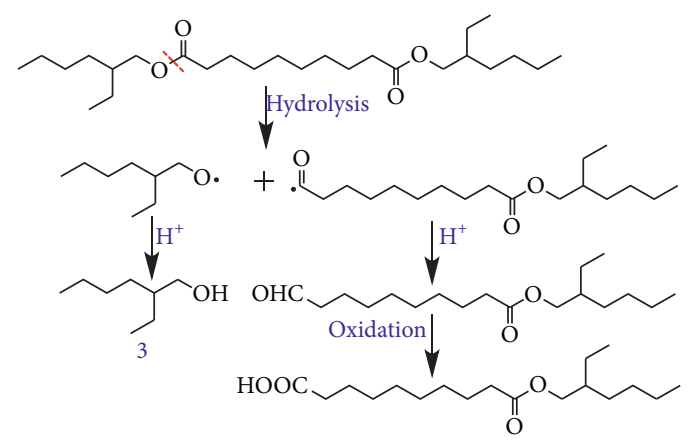

(a)
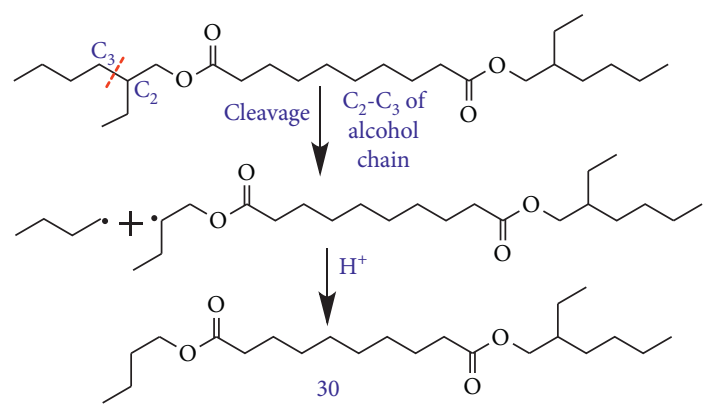

(b)

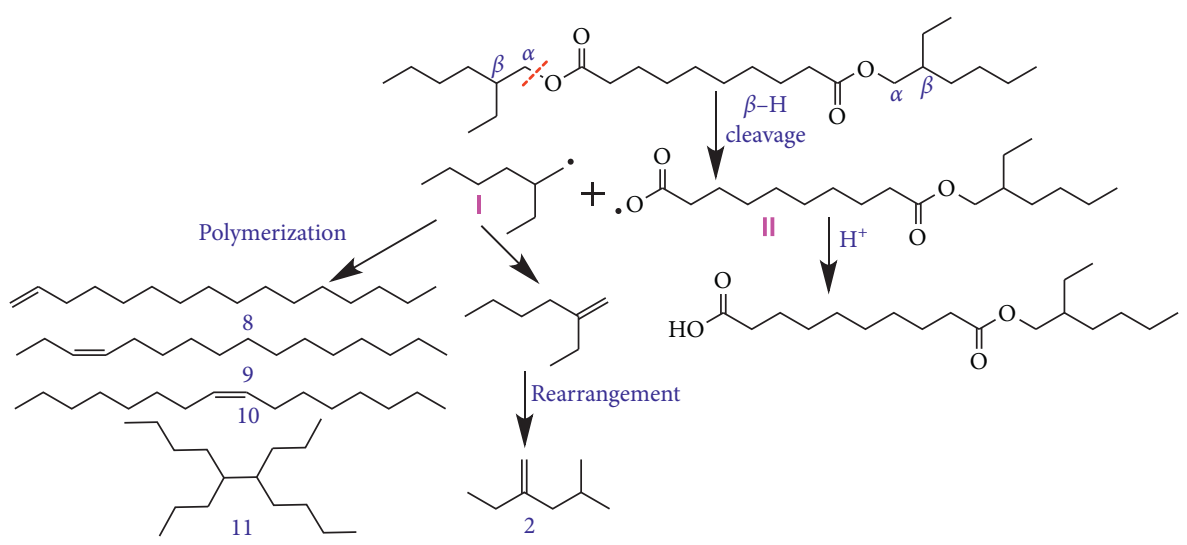

(c)

FIgURe 10: Continued. 


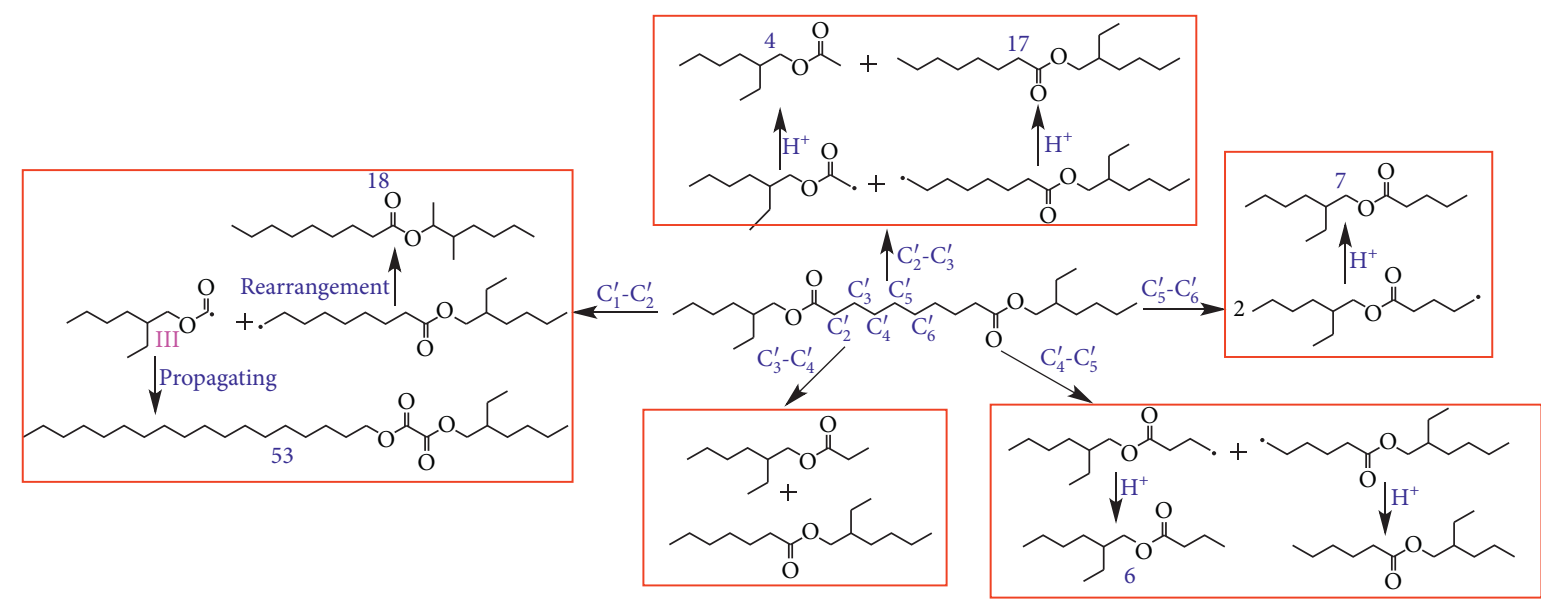

(d)

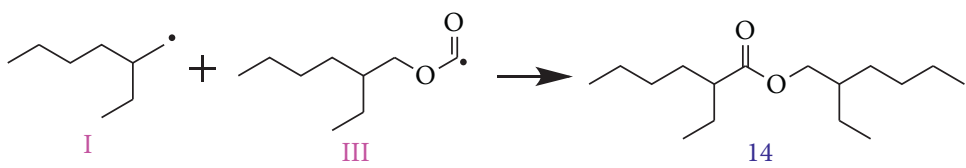

(e)

Figure 10: Possible mechanism for thermal oxidation of BEHDD. (a) Cleavage of the C-O ester bond, (b) cleavage of the $\mathrm{C}_{2}-\mathrm{C}_{3}$ bond in alcohol chain, (c) cleavage of the $\beta$-H bond in alcohol chain, (d) cleavage of the $\mathrm{C}-\mathrm{C}$ bond in ester chain, and (e) formation of compound $\mathbf{1 4}$.

decanedioate (30) (Figure 10(b)). As shown in Figure 10(c), cleavage of the $\beta-\mathrm{C}-\mathrm{H}$ bond can proceed via a six-membered cyclic intermediate at high temperatures to produce free radicals I and II. The latter can form 10-((2-ethylhexyl)oxy)-10oxodecanoic acid. In contrast, the former is an unstable eight carbon alkene that undergoes a number of chemical reactions, such as free radical rearrangement and chain propagation at high temperatures, to give 2-methyl-4-methylenehexane (2), hexadec-1-ene (8), $(Z)$-hexadec-3-ene (9), $(Z)$-hexadec-8-ene (10), and 5,6-dipropyldecane (11). Cleavage of the ester C-C bond can also occur, providing 2-ethylhexyl acetate (4), 2ethylhexyl butyrate (6), 2-ethylhexyl pentanoate (7), 2-ethylhexyl octanoate (17), 3-methylheptan-2-yl nonanoate (18), and 2-ethylhexyl octadecyl oxalate (53). Finally, free radicals I and III can combine to form 2-ethylhexyl 2-ethylhexanoate (14).

\section{Conclusions}

This work investigated the effects of heating on the properties of DEALOs. The main conclusions are as follows.

During the initial heating process, pyrolysis was the primary result, along with polycondensation. Antioxidants and antiwear agents were degraded to some extent to generate chromophores or auxochromes that darkened the oils. Degradation of the oils was relatively limited below $250^{\circ} \mathrm{C}$, with no obvious changes in the chemical constituents. The RC values for BEHDD at 270 and $300^{\circ} \mathrm{C}$ were significantly lower than that of the fresh oil, and analysis of the degradation mechanism showed that pyrolysis and cleavage of $\beta-\mathrm{C}-\mathrm{H}$ and $\mathrm{C}-\mathrm{C}$ bonds were the main contributors to decomposition. Lower molecular weight compounds, such as monoesters, diesters, alcohols, and olefins, were all generated at high temperatures. Polymerization produced a sludge while low-molecular-weight compounds generated by cracking dissolved almost completely in the oil sample, such that the viscosity and VI were relatively stable. The appearance of SMCs, including monoesters, alcohols, and olefins, as well as acidic derivatives of additives, greatly increased the NA values of the oil samples. These compounds can improve the strength of oil films and enhance the lubrication ability of the oil to some extent.

\section{Data Availability}

All data generated or analyzed during this study are included in this article.

\section{Conflicts of Interest}

The authors declare no conflicts of interest.

\section{Acknowledgments}

This research was funded by the Anhui Provincial Natural Science Foundation of China (grant no. 1908085ME162), the Open Research Project of Anhui Simulation Design and Modern Manufacture Engineering Technology Research Center (Huangshan University; grant no. SGCZXZD1902), and the Jiangsu Provincial Natural Science Foundation of China (grant no. BK20191155).

\section{References}

[1] Q. A. Ricardo, M. S. Roseli, C. C. Reinaldo, M. Norbert, and L. P. Carmem, "The determination of trace metals in lubricating oils by atomic spectrometry," Spectrochimica Acta Part B: Atomic Spectroscopy, vol. 62, pp. 952-961, 2007. 
[2] S. Pehan, M. S. Jerman, M. Kegl, and B. Kegl, "Biodiesel influence on tribology characteristics of a diesel engine," Fuel, vol. 88, no. 6, pp. 970-979, 2009.

[3] J. Wakiru, L. Pintelon, P. Chemweno, and P. Muchiri, "Analysis of lubrication oil contamination by fuel dilution with application of cluster analysis," in Proceedings of the XVII International Scientific Conference on Industrial Systems (IS'17), University of Novi Sad, Novi Sad, Serbia, October 2017.

[4] Z. H. Ye, Research on dynamic behavior of high-speed rolling bearings in aero-engines, Ph.D. thesis, Harbin Institute of Technology, Harbin, China, 2013, in Chinese.

[5] A. R. Lansdown and S. Lee, "Aviation lubricants," in Chemistry and Technology of Lubricants, R. M. Mortier, M. F. Fox, and S. T. Orszulik, Eds., pp. 345-351, Springer, Berlin, Germany, 3rd edition, 2010.

[6] W. M. Liu, J. Xu, D. P. Feng, and X. B. Wang, "The research status and prospect of synthetic lubricating oils," Tribology, vol. 33, pp. 91-104, 2013.

[7] S. J. Ruan, Y. W. Fei, J. Ma, J. T. Hao, X. C. Peng, and F. Guo, "Analysis on the correlation of physical and chemical Indexes of high temperature oxidation products of hydrocarbon aviation oil," Lubrication Engineers, vol. 43, pp. 111-115, 2018.

[8] L. L. Ge, Y. X. Liang, and J. J. He, "Study on thermal oxidation mechanism of ester base oil," China Petroleum Processing and Petrochemical Technology, vol. 47, pp. 88-93, 2016.

[9] P. Nagendramma and S. Kaul, "Development of ecofriendly/ biodegradable lubricants: an overview," Renewable and Sustainable Energy Reviews, vol. 16, no. 1, p. 764, 2012.

[10] G. F. Simmons and S. B. Glavatskih, "Synthetic lubricants in hydrodynamic journal bearings: experimental results," Tribology Letters, vol. 42, no. 1, pp. 109-115, 2011.

[11] N. A. Raof, R. Yunus, U. Rashid, N. Azis, and Z. Yaakub, "Effect of molecular structure on oxidative degradation of ester based transformer oil," Tribology International, vol. 140, p. 105852, 2019.

[12] P. Nagendramma, "Study of pentaerythritol tetraoleate ester as industrial gear oil," Lubrication Science, vol. 23, no. 8, pp. 355-362, 2011.

[13] Z. Li, Y. f. Lu, C. Zhang, J. L. Dong, X. L. Zhao, and L. Q. Wang, "Traction behaviours of aviation lubrication oil and the effects on the dynamic and thermal characteristics of high-speed ball bearings," Industrial Lubrication and Tribology, vol. 72, pp. 15-23, 2020.

[14] J. Y. Yang and Z. G. Yan, Synthetic Lubricants, pp. 5-123, China Petrochemical Press, Beijing, China, 1993, in Chinese.

[15] J. J. Tang, "Lecture on basic knowledge of synthetic lubricants(2)," Lube Oil, vol. 14, pp. 59-64, 1999, in Chinese.

[16] Y. Wu, W. Li, M. Zhang, and X. Wang, "Oxidative degradation of synthetic ester and its influence on tribological behavior," Tribology International, vol. 64, pp. 16-23, 2013.

[17] B. Vengudusamy, C. Enekes, and R. Spallek, "EHD friction properties of ISO VG 320 gear oils with smooth and rough surfaces," Friction, vol. 8, no. 1, pp. 164-181, 2020.

[18] S. Bian, Y. W. Fei, T. Yao, H. W. Yang, H. Z. Jiang, and F. Guo, "Monitoring the high-temperature oxidation stability of ester aviation lubricating base oil using high-pressure differential scanning calorimetry," Journal of Henan Normal University, vol. 44, pp. 65-69, 2016, in Chinese.

[19] K. J. Jiang, Z. J. Wang, and Y. S. Zhai, "Oxidation stability of aircraft lubricating oils," Journal of Materials Engineering, vol. 27, pp. 24-26, 1999, in Chinese.

[20] Y. Zong, X. F. Jiang, C. W. Yue, and Y. P. Xiao, "Study on thermal oxidation stability of aviation lubricatingoil under high temperature," Lube Oil, vol. 30, pp. 19-21, 2015, in Chinese.

[21] M. Fan, J. Ai, S. Zhang et al., "Lubricating properties of ester oil prepared from bio-based 2,5-furandicarboxylic acid," Friction, vol. 8, no. 2, pp. 360-369, 2020.

[22] B. K. Sharma and A. J. Stipanovic, "Development of a new oxidation stability test method for lubricating oils using highpressure differential scanning calorimetry," Thermochimica Acta, vol. 402, no. 1-2, pp. 1-18, 2003.

[23] C. D. Gamlin, N. K. Dutta, N. Roy Choudhury, D. Kehoe, and J. Matisons, "Evaluation of kinetic parameters of thermal and oxidative decomposition of base oils by conventional, isothermal and modulated TGA, and pressure DSC," Thermochimica Acta, vol. 392-393, pp. 357-369, 2002.

[24] Z. G. Zhang, L. B. Chen, L. Q. Song, and H. W. Wang, "Study on degradation of antioxidant additive in an aviation lubricating oil," Lubrication Engineering, vol. 39, pp. 112-114, 2014, in Chinese.

[25] M. Kohler and N. V. Heeb, "Characterization of ageing products of ester-based synthetic lubricants by liquid chromatography with electrospray ionization mass spectrometry and by electrospray ionization (tandem) mass spectrometry," Journal of Chromatography A, vol. 926, no. 1, pp. 161-165, 2001.

[26] M. Frauscher, C. Besser, G. Allmaier, and N. Dörr, "Oxidation products of ester-based oils with and without antioxidants identified by stable isotope labelling and mass spectrometry," Applied Sciences, vol. 7, no. 4, p. 396, 2017.

[27] X. Qian, Y. Xiang, H. Shang, B. Cheng, S. Zhan, and J. Li, "Thermal-oxidation mechanism of dioctyl adipate base oil," Friction, vol. 4, no. 1, pp. 29-38, 2016.

[28] Y. Jin, H. Duan, L. Wei et al., "Comparison of the oxidation resistance of synthetic ester oils DOA and TDTM: experimental evaluation and theoretical calculation," Lubrication Science, vol. 31, no. 6, pp. 252-261, 2019.

[29] C. M. Murphy and H. Ravner, "Oxidation characteristics of some diester fluids," Industrial \& Engineering Chemistry, vol. 44, no. 7, pp. 1607-1612, 1952.

[30] A. Ali, F. Lockwood, E. E. Klaus, J. L. Duda, and E. J. Tewksbury, "The chemical degradation of ester lubricants," A S L E Transactions, vol. 22, no. 3, pp. 267-276, 1979.

[31] Z. Gan, T. Yao, M. Zhang, J. Hu, X. Liao, and Y. Shen, "Effect of temperature on the composition of a synthetic hydrocarbon aviation lubricating oil," Materials, vol. 13, no. 7, p. 1606, 2020.

[32] D. Kealey and P. J. Haines, Instant Notes in Analytical Chemistrypp. 233-241, Taylor \& Francis, London, UK, 1st edition, 2002.

[33] S. Zzeyani, M. Mikou, J. Naja, and A. Elachhab, "Spectroscopic analysis of synthetic lubricating oil," Tribology International, vol. 114, pp. 27-32, 2017.

[34] T. Yao, H. W. Yang, Y. W. Fei, F. Guo, L. Guo, and S. Bian, "Hyperchromic effect of antioxidants on aero lubricating oil under metal action," Acta Petrol Sin, vol. 34, pp. 307-315, 2018, in Chinese.

[35] T. Yao, J. T. Hao, L. Guo et al., "The relationship between structure and property about poly $\alpha$-olefin aviation lubricating base oil at high temperature condition," Lubrication Engineering, vol. 41, pp. 91-95, 2016, in Chinese.

[36] K. Tamura and T. Nakano, "The hydrodynamic radii of viscosity index improvers for lubricant oils," Tribology Online, vol. 14, no. 4, pp. 188-193, 2019.

[37] I. Stanciu, "Viscosity index for soybean oil," MAGNT Research Report, vol. 5, pp. 447-449, 2018. 
[38] I. Stanciu, "Viscosity index for oil used as biodegradable lubricant," Indian Journal of Science and Technology, vol. 13, no. 3, pp. 352-359, 2020.

[39] P. Mousavi, D. Wang, C. S. Grant, W. Oxenham, and P. J. Hauser, "Effects of antioxidants on the thermal degradation of a polyol ester lubricant using GPC," Industrial \& Engineering Chemistry Research, vol. 45, no. 1, pp. 15-22, 2006.

[40] P. Mousavi, D. Wang, C. S. Grant, W. Oxenham, and P. J. Hauser, "Measuring thermal degradation of a polyol ester lubricant in liquid phase," Industrial \& Engineering Chemistry Research, vol. 44, no. 15, pp. 5455-5464, 2005.

[41] S. Siouris and C. W. Wilson, "Thermodynamic properties of pentaerythritol-based species involved in degradation of aviation gas turbine lubricants," Industrial \& Engineering Chemistry Research, vol. 49, no. 23, pp. 12294-12301, 2010.

[42] R. Kreivaitis, J. Padgurskas, M. Gumbytè, V. Makarevičienè, and B. Spruogis, "The influence of oxidation on tribological properties of rapeseed oil/oksidacijos itaka rapsụ aliejaus tribologinèms savybėms/Влияние Оксидации РаШсовоГо Масла На ЕГо ТриболоГические Свойства," Transport, vol. 26, no. 2, pp. 121-127, 2011.

[43] S. Q. A. Rizvi, A Comprehensive Review of Lubricant Chemistry, Technology, Selection, and Design, ASTM International, Conshohocken, PA, USA, pp. 47-97, 2009.

[44] M. A. Maleque, H. H. Masjuki, and A. S. M. A. Haseeb, "Effect of mechanical factors on tribological properties of palm oil methyl ester blended lubricant," Wear, vol. 239, no. 1, pp. 117-125, 2000.

[45] X. M. Chen, S. Y. Li, G. Y. Li, X. S. Ni, Z. C. Cheng, and Z. J. Zhao, "Discussion of sample pretreatment methods for determination of acid number in lubricants," Instrumentation Analysis Monitoring, vol. 42, pp. 1297-1300, 2013, in Chinese.

[46] B. R. Moser, B. K. Sharma, K. M. Doll, and S. Z. Erhan, "Diesters from oleic acid: synthesis, low temperature properties, and oxidation stability," Journal of the American Oil Chemists' Society, vol. 84, no. 7, pp. 675-680, 2007.

[47] W. T. Zhang, J. L. Li, P. X. Xiao, H. J. Wu, and S. Yang, "The relationship between acid value and lubricating oil performance," Petroleum Products Application Research, vol. 32, pp. 65-69, 2014, in Chinese.

[48] Y. W. Fei, Z. S. Cheng, H. W. Yang, and T. Yao, "Property analysis of aviation lubricant base oil synthesized from ester," Contemporary Chemical Industry, vol. 42, pp. 1297-1300, 2013, in Chinese.

[49] Q. Zhang and W. W. Shi, "Progress of the synthesis and friction reducing properties study of oiliness agent," Lubrication Engineering, vol. 39, pp. 114-118, 2014, in Chinese.

[50] H. Cen, A. Morina, and A. Neville, "Effect of lubricant ageing on lubricants' physical and chemical properties and tribological performance; Part I: effect of lubricant chemistry," Industrial Lubrication and Tribology, vol. 70, no. 2, pp. 385392, 2018.

[51] L. S. Pamela, H. P. Gerald, and T. R. Alan, "The development of a standard method for determining oxidation induction times of hydrocarbon liquids by PDSC," Thermochimica Acta, vol. 243, pp. 201-208, 1994.

[52] F. M. T. Luna, B. S. Rocha, E. M. Rola Jr. et al., "Assessment of biodegradability and oxidation stability of mineral, vegetable and synthetic oil samples," Industrial Crops and Products, vol. 33, no. 3, pp. 579-583, 2011.

[53] H. Zhang, X. L. Gao, Z. Cheng, and L. Wu, "The study on tribological behaviors of the synthetic ester as lubricant base oil," Journal of Central China Normal University, vol. 46, pp. 440-443, 2012, in Chinese.

[54] J. Lahijani, F. E. Lockwood, and E. E. Klaus, "The influence of metals on sludge formation," A S L E Transactions, vol. 25, no. 1, pp. 25-32, 1982.

[55] L. B. Chen and S. H. Guo, "The development of research on thermal oxidation and condition monitoring of ester lubricants," Synthetic Lubricant, vol. 28, pp. 19-24, 2001.

[56] W. G. Xue, X. G. Zhou, and J. M. Li, "Research on current status and progress of lubricants antioxidants," Synthetic Lubricant, vol. 40, pp. 7-13, 2013.

[57] T. Yao, H. W. Yang, L. Guo et al., "The deterioration mechanism of diester aero lubricating oil at high temperature," Journal of Spectroscopy, vol. 2017, Article ID 5392864, 8 pages, 2017. 